\title{
Persuasión y Personalidad. El receptor en la comunicación persuasiva.
}

Persuasion and Personality. The receiver in persuasive comunication.

Iván Sánchez Muñoz ${ }^{1}$

María Luisa Calcerrada Alcazar ${ }^{2}$

José Luis González Álvarez ${ }^{3}$

Manuel de Juan Espinosa ${ }^{1}$

(1) Instituto de Ciencias Forenses y de la Seguridad. Universidad Autónoma de Madrid, Madrid, España. (2) Sección de Análisis del Comportamiento Delictivo. Guardia Civil, Madrid, España. (2) Gabinete de Coordinación y Estudios. Secretaría de Estado de Seguridad, Madrid, España.

Email correspondencia: ivansanchez220794@gmail.com

\section{Resumen}

La persuasión se viene estudiando desde la psicología social. Este enfoque, si bien efectivo, puede resultar generalista para diversas situaciones interindividuales como las ventas, negociación e interrogatorios, o los tratamientos clínicos. Por ello también cabría enfocar el estudio de la persuasión desde el enfoque de las diferencias individuales. ¿Habrá técnicas de persuasión más efectivas con unos sujetos que con otros? Partiendo del receptor como centro del proceso persuasivo, se presenta una revisión de los estudios que se han ocupado de la influencia de los rasgos de personalidad del receptor en el cambio de actitudes. Se encuentra que destacan la tendencia a la extroversión, neuroticismo, empatía y baja necesidad de cognición como vulnerabilidades a persuasión por la vía periférica. Sus contrapartes resultan más resistentes a persuasión, siendo necesario el empleo de la vía central. Finalmente, en base a estudios sobre la vulnerabilidad a las estrategias de persuasión de Cialdini, se proponen hipótesis de relación entre estas vulnerabilidades y los rasgos de personalidad más estudiados con respecto a la persuasión.

Palabras clave: persuasión, rasgos de personalidad, diferencias individuales, perfiles de persuasión, personalidad.

\begin{abstract}
Persuasion has been studied and used as part of social psychology. This perspective, although effective, can be found to be too generalist for a variety of interindividual situations such as sales, negotiations and questionings, or medical treatment Thus we should focus the persuasion research from the point of the individual differences. Is it possible to make persuasive tactics more effective when applied to a particular individual? Having chosen the receptor as the center of the persuasion process, this review presents a collection of studies that have dealt with the effect of the receptor's personality traits on changes in attitude. Tendency to extrovertism, neurocitism, empathy and low need for cognition are noticeable vulnerabilities highlighted in this paper. On the other hand, according to Cialdini's persuasion strategies researches into susceptibility, some hypothesis are suggested. These implicate the relation between vulnerabilities mentioned and most researched personality traits in persuasion.
\end{abstract}

Keywords: persuasion, personality traits, individual differences, persuasion profiles, personality.

Fecha de envío: 15/07/2018

Fecha de aceptación: 28/09/2018 


\section{INTRODUCCIÓN}

Se entiende por persuasión "cualquier cambio que se dé en las actitudes de un sujeto como consecuencia de una exposición a un proceso comunicativo diseñado y ejecutado con esta finalidad" (Briñol, de la Corte y Becerra, 2001; Petty y Cacioppo, 1986). Los términos "cambio de actitudes" e "influencia" se suelen utilizar como sinónimos de persuasión (Briñol et al., 2001; McGuire, 1985; Petty y Cacioppo, 1986), por lo que en el presente artículo también se utilizarán indistintamente. Como el estudio de las actitudes (características, formación, funciones, medición,) ha ocupado una posición central en la Psicología Social durante décadas (Vázquez y Gómez, 2018), también es el enfoque social el que viene primando en el estudio de los factores que las modifican.

Modelos clásicos como el de Hovland (1949;1953) y más adelante el de McGuire (1985) plantean la persuasión como un fenómeno en el que el receptor es un sujeto pasivo, el cual recibe la información, y modificará su actitud y seguramente su conducta en función de distintos procesos (Páez, Fernández, Ubillos y Zubieta, 2004).

Posteriormente, la teoría de la respuesta cognitiva, propuesta por Greenwald (1968), destaca el papel de los procesos mentales en el cambio de actitudes. Este modelo defiende el notable peso de los pensamientos que surgen en el receptor cuando se expone al proceso comunicativo (Greenwald, 1968; Igartua, 1998). Aquí la persuasión será más o menos efectiva en función de la cantidad, polaridad (positiva o negativa) y fuerza de las cogniciones de la audiencia. Así, el receptor no es un sujeto pasivo, sino activo (Briñol et al., 2001; Igartua, 1998; Petty, Cacioppo y Goldman, 1981).

Finalmente, la propuesta que ha cobrado mayor interés ha sido el modelo de probabilidad de elaboración (Elaboration Likelyhood Model, ELM), que en la actualidad cuenta con el fundamento teórico más completo y sólido en el estudio de la influencia, basándose en la necesidad de las personas de tener una actitud correcta sobre todos los elementos de la vida cotidiana (Petty y Cacioppo, 1986).

El ELM diferencia dos rutas en el proceso de persuasión: central y periférica. La ruta central implica la atención, asimilación, el procesamiento y la elaboración de la información que contiene el mensaje, por parte del receptor. Por la vía periférica, el receptor no dedica tanto esfuerzo al procesamiento del contenido del mensaje, sino que se deja guiar por indicadores situacionales. Los cambios actitudinales ( $\mathrm{y}$, por tanto, comportamentales) que se produzcan por la vía central serán más consistentes y a largo plazo que por la vía periférica (Briñol, et al., 2001).

La probabilidad de elaboración variará en función de diversos factores, destacándose la motivación y la capacidad como ejes centrales, pero dependiendo de otros, como la implicación en el tema, la actitud previa, la complejidad del mensaje, o los conocimientos previos del receptor, por citar algunos (Petty y Wegener, 1998; 1999).

Para llegar a la persuasión, se suele atender más a la vía periférica que a la central, debido a su mayor funcionalidad práctica. Sobre este tipo de procesamiento más periférico cabe citar las aportaciones de Robert Cialdini (1987), que habla de las reacciones "Click-zoom", o procesos automáticos (i.e., con escaso procesamiento de información) que se dan en las situaciones que corresponden a la comunicación por vía periférica. Relacionados con este tipo de procesamiento, destacó seis principios de persuasión: reciprocidad, coherencia, sanción social, autoridad, simpatía y escasez.

Cabe preguntarse si cada uno de esos principios opera por igual en todos los individuos, o si, por el contrario, algunas personas son más vulnerables a unos que a otros en función de su forma de ser, o personalidad. La Psicología Social ya ha venido explicando que algunas variables personales del receptor o de la audiencia pueden influir en la persuasión: la inteligencia, la necesidad de cognición, el estado de ánimo, la postura corporal, la experiencia subjetiva, $y$, en fin, la implicación personal (Vázquez y Gómez, 2018). Por lo que también cabe preguntarse por el efecto que puedan tener las diferencias individuales en personalidad. No en vano hay numerosos escenarios en la vida cotidiana en los que puede interesar la gestión de esos efectos para facilitar la persuasión de determinados sujetos en particular. Por poner un ejemplo, a los negociadores policiales les interesa que un secuestrador o un tomador de rehenes deponga una actitud violenta y beligerante en beneficio de la resolución pacífica del incidente, para lo cual quizá sea relevante atender a su forma de ser durante el proceso comunicativo de la negociación, que no dejara de ser a la vez un proceso persuasivo.

En esta línea, aplicándolo al marketing y las ventas, Kaptein ya ha estudiado la diferente vulnerabilidad de cada sujeto a los distintos principios de influencia de Cialdini (Kaptein y Markopoulos, 2009; Kaptein, 2012; 2015; Kaptein y Eckles, 2012). Este autor lleva a cabo estudios en los que, a través de su cuestionario STPS (Susceptibility To Persuasion Scale) (Kaptein, 2012) genera 
perfiles de persuasión de cada individuo.

Así, se puede suponer que debería existir algún tipo de relación entre la forma de ser y la vulnerabilidad a ser persuadido. De modo que a los emisores de los mensajes persuasivos les convendría conocer antes la estructura de personalidad de los receptores de esos mensajes.

Clonninger (2003) definió la personalidad, en el marco de la psicología de las diferencias inviduales, como "las causas internas que subyacen al comportamiento individual y a la experiencia de la persona". Para determinar la personalidad de un sujeto, se distinguen tres enfoques: tipos, rasgos y factores. El enfoque del tipo sitúa al sujeto en una única categoría de varias, siendo todas estas excluyentes. Por su parte, la teoría de rasgo pasa de lo cualitativo a lo cuantitativo, dividiendo la personalidad del individuo en varios elementos medibles (rasgos), que la convierte en un enfoque más descriptivo y flexible, así como al rasgo en la unidad de análisis más empleada (Moreno, 2007). Los factores, siendo muy similares a los rasgos, suponen un enfoque más amplio y estadístico, así como menos explicativo.

Entre los distintos modelos multirasgo propuestos, los dos más extendidos son, quizá, el Big Five y el PEN. El primero divide la personalidad en cinco rasgos: neuroticismo, extroversión, apertura a la experiencia, amabilidad y responsabilidad. Por su parte, el PEN destaca solo tres rasgos: mantiene el neuroticismo, incluye la apertura en el rasgo de la extroversión, y une los rasgos de amabilidad y responsabilidad en el de psicoticismo (de Juan y García, 2004), postulando una base biológica para los rasgos, frente a la más estadística del Big Five (Cloninger, 2003).

Por todo lo expuesto, en este trabajo se plantea una revisión bibliográfica que recopile los distintos estudios que aborden el fenómeno de la persuasión en relación con la personalidad, primando el modelo del rasgo.

\section{MÉTODO}

Primero se ha empleado el motor de búsqueda de EBSCOhost, que ha permitido una búsqueda simultánea a través de PsycInfo, PcycArticles, PsycBooks, PubMed y Psychology and Behavioral Science Collection. Luego se han replicado las búsquedas en Science Direct y Web of Science, utilizándose los tesauros persuasion, influence, attitude, attitude change, Petty, Cialdini, Brinol, Cacioppo, Falces, Greenwald, Hangtvedt, Albarracin, Igartua, Kaptein, personality, personality traits, individual differences, extraversion y empathy, buscando tanto por título, como por palabras clave, o aparición en el resumen.

Debido a la limitada cantidad de bibliografía encontrada, no se ha realizado filtro por fecha de publicación, si bien se ha dado más peso a las publicaciones más actuales (24 referencias posteriores al año 2000).

En la tabla 1 del Anexo se muestran las distintas búsquedas que arrojaron resultados, así como el número de artículos que se seleccionaron ("Selección”) tras una lectura de los abstract de cada uno de ellos, empleando solo los artículos y libros que tratasen la relación entre personalidad y persuasión, ya fuese de un modo directo o indirecto.

Posteriormente se procedió a realizar una última búsqueda en base a las referencias bibliográficas de cada uno de los artículos encontrados.

Tras la lectura del material encontrado, se realizó la selección final (tabla 2) en función de la importancia y validez de los datos que aportasen, resultando un total de 35 referencias.

Tabla 2. Resumen del número de artículos seleccionados

\begin{tabular}{cccccc}
\hline \hline Busqueda & EBSCO & SD & WoS & POST & Total \\
\hline B1 & 4 & 1 & & & \\
\hline B2 & 4 & & & & \\
\hline B5 & 4 & & 1 & & \\
\hline B6 & 1 & & & & \\
\hline B7 & 1 & & & & \\
\hline B9 & & & 3 & 14 & 35 \\
\hline B10 & & & 6 & 14 & \\
\hline POST & & 14 & 6 & & \\
\hline Total & 14 & & & & \\
\hline \hline
\end{tabular}

\section{RESULTADOS}

De las 35 referencias mencionadas, 15 ponen en relación la vulnerabilidad a la persuasión con la personalidad empleando el modelo Big Five. Los restantes utilizan escalas distintas para medir los respectivos rasgos. Pero casi todas se centran principalmente en los rasgos de extroversión, neuroticismo, empatía y necesidad de cognición. Por ello, en este artículo se van a ordenar los resultados conforme al modelo PEN de Eysenck, de tres rasgos: Psicoticismo (estrechamente relacionado con la empatía), Extraversión y Neuroticismo. La gran ventaja de este modelo de personalidad es que los tres rasgos cuentan 
con una sólida base biológica, lo que lo hace uno de los modelos más sencillos de entender por personas legas en psicología $\mathrm{y}$, por tanto, más útiles a la hora de perfilar fácilmente a los receptores del proceso persuasivo.

Se entiende como extrovertido al individuo activo, vivaz, dominante, sociable y buscador de estimulaciones (Eysenck, 1990; McCrae, Costa y Piedmont, 1993). Hans J. Eysenck propone en su modelo biológico una explicación sobre estas características basada en la activación o arousal del neocórtex (mediada por el sistema de activación reticular ascendente, SARA), afirmando que el individuo extrovertido tendrá una hipoactivación cortical, al contrario que los introvertidos (Eysenck y Bordas, 1970; Hagemann et al., 2009). Así, se señalan como ejes centrales de la extroversión la sociabilidad y la búsqueda de sensaciones, siendo el medio para contrarrestar la naturaleza de su funcionamiento cerebral (Eaves y Eysenck, 1975; Eysenck, 1985; citado en Cloninger, 2003). Es de destacar además la relación entre la apertura a la experiencia del Big Five y el rasgo de extroversión del PEN (Aluja, García y García, 2002).

El neuroticismo es el rasgo de la emocionalidad, caracterizándose sus puntuaciones altas por la inestabilidad emocional, las tendencias depresivas y la preocupación ansiosa (Cattell y Cattell, 1995; Cloninger, 2003; Eysenck y Bordas, 1970; McCrae et al., 1993). Este rasgo estará relacionado con muchos factores mencionados en los estudios sobre cambio de actitudes, tal como la ansiedad "crónica" o la baja autoestima, la cual parece estar presente en individuos neuróticos, especialmente cuando este rasgo se interrelaciona con una baja extroversión (de Juan y García, 2004).

Se entiende por empatía la capacidad de experimentar las emociones de los otros (Moya-Albiol, Herrero, Bernal, 2010). Se han hallado evidencias acerca de las diferencias en los niveles de empatía en función de la actividad amigdalar, que se encuentra hipoactivada en aquellos sujetos con falta de empatía y miedo (Gleen y Raine, 2014; Moya-Albiol et al., 2010). Este término estará estrechamente ligado al rasgo de Psicoticismo.

Por su parte, la necesidad de cognición se define como la motivación intrínseca por la realización de tareas que suponen una actividad y esfuerzo cognitivo; esto es, una tendencia y disfrute de la actividad de pensar (Cacioppo y Petty, 1982; Falces, Briñol, Sierra, Becerra y Alier, 2001; Gutierrez, Bajen, Sintas y Amat, 1993). Del mismo modo que la extroversión supone una tendencia a la búsqueda de estimulación física, la necesidad de cognición implica la búsqueda de la estimulación cognitiva, caracterizándose los sujetos altos en dicha faceta por la realización de numerosas tareas con alta carga cognitiva, buscando constantemente explicación a todos los estímulos que los rodean, y reflexionando sobre los mismos (Briñol et al., 2001).

Como se ha dicho, para ordenar los distintos hallazgos, se presentarán los datos encontrados en función del rasgo al que hacen referencia.

\section{A. Extroversión}

Carment, Miles y Cervin (1965) llevaron a cabo un estudio en el cual generaron situaciones de comunicación en las que, por parejas, los individuos debatían sobre ciertas temáticas. Se midió la latencia de la primera intervención, la longitud de los argumentos de cada sujeto, y sus actitudes sobre el tema antes y después de la discusión. Encontraron que, al enfrentar a un extrovertido con un introvertido, el extrovertido resultaba más persuasivo, siendo el introvertido mucho más influenciable (Carment et al., 1965). Esto fue atribuido a su nivel de actividad y socialización, tendiendo a realizar la primera intervención el extrovertido.

Sin embargo, Salceanu (2014) destacó una baja resistencia a la persuasión por parte de los sujetos más abiertos a la experiencia. Esta discordancia podría deberse a la diferencia entre los paradigmas experimentales. El estudio de Carment et al. (1965) permitió observar las diferencias al confrontar a sujetos extrovertidos, con mayor actividad y dominancia, con sujetos más sumisos y pausados como los introvertidos. La impulsividad, dominancia y energía con la que intervienen los sujetos más extrovertidos podría estar inhibiendo la conducta de los sujetos introvertidos debido a un exceso de estimulación (Eysenck, 1970). La mayor riqueza y elaboración en los argumentos del extrovertido en esta situación sería la explicación de este fenómeno. Así, la medición del nivel de persuasión en esta interacción concreta no sería incompatible con el postulado de resistencia a la persuasión en términos más genéricos que propone Salceanu para estos sujetos más introvertidos. Estos últimos, siendo menos impulsivos y más meditativos, necesitarían, como norma general, de argumentos más complejos debido a su tendencia a la elaboración.

En la misma línea, Shakarchi y Haugtvedt (2004) comprobaron que los individuos que tendían a pensar en las consecuencias futuras (introvertidos), meditando más sobre la información que se les envía, presentaban una 
mayor resistencia a la influencia.

Chen y Lee (2008) diferenciaron entre las posiciones utilitaristas y hedónicas hacia diversas páginas web (de viajes y maquillaje) en función de los rasgos de personalidad. Encontraron una correlación positiva entre la extroversión y la apertura a la experiencia, con una tendencia a posiciones hedónicas. Esta tendencia la explicaron afirmando que los sujetos con estos rasgos tienden a procesar menos la toma de decisiones; son más impulsivos, dejándose llevar a la hora de tomar decisiones, sin preocuparse tanto por el control y la seguridad como le podría preocupar a un sujeto más introvertido, el cual tendía a las actitudes más prácticas o utilitaristas (Chen y Lee, 2008). Esto es, los sujetos extrovertidos parecían guiarse por una vía periférica, mientras que los introvertidos procesaban más la información.

Germeijs (2011) estudió la tendencia a la indecisión en relación a distintos rasgos de personalidad, encontrando, entre otras, una relación negativa significativa con la extroversión. Esto es, los introvertidos parecían tender más a la indecisión que los extrovertidos. Esto puede deberse al componente impulsividad que caracteriza al sujeto extrovertido, el cual, del mismo modo que en el estudio de Chen y Lee (2008), le inclina a procesar menos la información a la hora de tomar un posicionamiento, primando la vía periférica. Sus resultados concuerdan con los de Hodson y Sorrentino (1999), quienes ya habían encontrado correlación entre la apertura a la experiencia, y una falta de necesidad de resolver la incertidumbre.

Hepler y Albarracín (2013) encontraron que los sujetos extrovertidos y abiertos tendían a posicionarse de forma positiva. Esto se debe a la vivacidad que caracteriza a estos sujetos y su tendencia a la búsqueda de nuevas sensaciones, que los inclina a una posición de aceptación hacia aquellos estímulos novedosos.

Tras operativizar distintos componentes motivacionales en forma de oraciones, De Vries, Truong, Zaga y Evers (2017) pusieron a prueba su efectividad teniendo en cuenta la personalidad de los receptores. Encontraron que los sujetos con altos niveles de extroversión se veían más atraídos por las oraciones que hacían referencia a un componente social. Por su parte, los sujetos con alta apertura a la experiencia parecían no valorar el impacto de sus acciones en el entorno, pero sí las causas de su comportamiento.

\section{B. Neuroticismo}

Desde mediados del siglo XX autores como Hovland (1953), Millman (1968), McGuire (1985) o Hodson y
Sorrentino (Hodson y Sorrentino, 1999; Sorrentino, Bobocel, Gitta, Olson y Hewitt, 1988) ya planteaban la importancia de la autoestima en la persuasión. Janis (1954) concluyó en sus estudios que la baja autoestima correlacionaba con la susceptibilidad a la persuasión, del mismo modo que Robinson (1941) había observado lo mismo con la tendencia depresiva. Estas suponen una propensión inhibitoria que podría facilitar la aceptación de argumentos ajenos, viendo los propios como menos válidos. Del mismo modo, Higbee (1969) destacó ciertas vulnerabilidades en los sujetos de autoestima baja. Señaló la mayor efectividad de los mensajes amenazantes en los sujetos con mayor autoestima, los cuales se pueden sobreponer a la situación y elaborar adecuadamente la información, a diferencia de los que tienen una autoestima más baja, que tienden a la evitación (Leventhal y Trembly, 1968). Además, se encontró que los sujetos con poca autoestima son más susceptibles a mensajes que apelan a la culpabilidad (Zemach, 1966; citado en Highbee, 1969).

Zellner (1970) realizó un estudio diferenciando tres condiciones: persuasión directa, sugestión y conformidad. Observó que los sujetos con niveles altos de autoestima eran los más susceptibles a persuasión directa, siendo más fácil persuadirlos por la vía central, mientras que los más susceptibles a la sugestión eran los sujetos con autoestima media.

Por su parte, Hepler y Albarracín (2013) observaron que los sujetos más emocionales tienden a ser más negativos en primera instancia hacia cualquier estímulo novedoso. Este posicionamiento negativo puede llevarles a la evitación de la toma de decisiones en muchas ocasiones, siendo la explicación que propusieron Germeijs y Verschueren (2011) en su estudio para la alta correlación entre neuroticismo y tendencia a la indecisión.

Shakarchi y Haugtvedt (2004) observaron una mayor resistencia a la persuasión en aquellos sujetos que prestaban más atención a las consecuencias futuras. Esto refiere a una evaluación de las consecuencias. Sin embargo, más que fijarse en las consecuencias, los individuos neuróticos tienden a preocuparse por estas de modo ansioso. Así, si bien los sujetos neuróticos tienen más vulnerabilidades a la persuasión, un estado ansioso (al que tienen cierta tendencia) bloquea la adecuada elaboración de la información. Esto coincide con los estudios sobre mensajes amenazantes ya mencionados (Leventhal y Trembly, 1968), así como con las observaciones de DeBono y McDermott (1994), quienes señalaron que los sujetos ansiosos tenderían a guiarse por indicadores periféricos, como podría ser el atractivo, 
mientras que los menos ansiosos serían más fáciles de persuadir por la vía central (Briñol y Petty, 2005).

Halko y Kientz (2010) pusieron a prueba varios métodos de persuasión para inducir estilos de vida saludables. Estos giraban en torno al tipo de liderazgo de un instructor (autoritario o no autoritario), el tipo de actividad a nivel social (cooperativo o competitivo), el tipo de motivación (extrínseca e intrínseca) y el tipo de refuerzo (positivo o negativo). Encontraron que los sujetos neuróticos se veían reacios al trabajo social, tanto cooperativo como competitivo.

Estudios recientes han encontrado que los sujetos con mayor autoestima son más resistentes a la persuasión, mientras que los neuróticos parecen ser más vulnerables debido a su inseguridad (Oreg y Sverdlik, 2014).

\section{Empatia}

La empatía se ha estudiado en relación con la persuasión induciendo un estado anímico, o proponiendo situaciones de similaridad entre el receptor y distintos elementos del proceso comunicativo.

Igartua (2010) estudió el fenómeno de identificación con los personajes de una historia para comprobar la efectividad de la persuasión narrativa. Encontró que los sujetos que se identificaban con el personaje elaboraban mucho más la información, prediciendo además este fenómeno el estado emocional del receptor, y dándose una mayor persuasión. Este resultado fue replicado por Komeda, Tsunemi, Inohara, Kusumi y Rapp (2013), los cuales indujeron "empatía por similaridad", encontrando que los sujetos que se identificaban tanto con el protagonista como con el argumento del mensaje tendían a un mayor cambio actitudinal.

Cai, Pan y He (2014) llevaron a cabo un experimento parecido, poniendo a prueba la relación entre la carga emocional del mensaje y el estado anímico del receptor, es decir, construyendo una situación empática. Estos observarpn que los sujetos cuyo estado anímico era congruente con el mensaje se orientaban a una mayor aceptación del mensaje.

Todos estos datos concuerdan con los ofrecidos por Briñol y Petty en "Individual differences in attitude change", capítulo del libro "Handbook of attitudes" (Albarracín et al., 2014). Estos dos autores destacaron la relación positiva entre la similaridad en los rasgos de extroversión (Chang, 2002; citado en Briñol y Petty, 2005) y dominancia (Moon, 2002; citado en Briñol y Petty, 2005) entre emisor y receptor, y el éxito en la persuasión.
El equipo de Hirsh también logró replicar estos resultados en su experimento, en el que se pusieron a prueba distintos anuncios que hacían referencia a rasgos de personalidad del Big Five. Se encontró que la similaridad entre el anuncio y la personalidad del receptor contribuía a la eficacia persuasiva del mensaje (Hirsh, Kang y Bodenhausen, 2012). Los distintos tipos de personalidad reflejan ciertas tendencias y necesidades: del mismo modo que el extrovertido tiende a la estimulación y actividad, el neurótico busca seguridad. Parece que los mensajes son más persuasivos cuando proponen o sugieren una satisfacción de estas necesidades; cuando son congruentes con su personalidad (Hirsh et al., 2012).

Por otra parte, la similaridad emisor-receptor y mensaje-receptor parece ser una buena fuente de empatía (Igartua, 2010; Komeda et al., 2013). Si, como sugieren Cai et al. (2014) esta empatía "artificial" (o inducida) conlleva una mayor probabilidad en la aceptación del mensaje, cabría esperar que los sujetos más empáticos a nivel de rasgo fuesen más fáciles de persuadir, tendiendo estos a asimilar las emociones ajenas. Esta hipótesis tendría su sustento en el estudio de Salceanu (2014), quien encontró relación entre la resistencia a la persuasión y los niveles bajos de empatía.

Por su parte, Shen (2011) encontró una relación positiva directa e indirecta entre la empatía y la efectividad en la persuasión. Del mismo modo que señalan otros estudios, concluyó que los sujetos empáticos, con facilidad de ponerse en lugar de otros, eran más fáciles de persuadir, añadiendo que esta empatía mitiga la reactancia, eliminando otra barrera para la influencia.

\section{Necesidad de cognición}

Petty et al. (1983) realizaron un estudio en el que midieron la cantidad y calidad del procesamiento de los individuos en función de sus niveles de necesidad de cognición. Se encontró que los sujetos con altos niveles de este rasgo tendían a procesar en mayor medida el mensaje, elaborándolo y generando actitudes más fuertes. Los sujetos con alta necesidad de cognición diferenciaban bien los argumentos según su "fuerza", de manera que el mejor modo de influir en estos mismos era por una vía central.

Más adelante, Berzonsky y Sullivan (1992) relacionaron este rasgo con su teoría de la identidad, y los tres estilos de identidad que propone en ella: informativo, normativo y evitativo (Berzonsky, 1989). El experimento confirmó su hipótesis sobre la relación entre la necesidad de cognición y el estilo informativo, caracterizando a estos 
sujetos por un mayor escrutinio de información y una actitud activa en la toma de decisiones. Se guían por la información que recogen y analizan (correlación de 0,50), no dejándose llevar por indicadores periféricos tales como el atractivo o el estatus (Bezonsky y Sullivan, 1992).

Por su parte, Haugtvedt y Petty (1992) expusieron a distintos sujetos a productos nuevos, e "induciéndoles" una actitud hacia ellos, para recoger la actitud que mantenían dos días después. Encontraron que los sujetos con alta necesidad de cognición generaban actitudes más fuertes que sus contrarios. Estas eran más persistentes en el tiempo, a la vez que más resistentes a persuasión.

\section{E. Influencia y personalidad}

Tras esta revisión, se observa que el estudio de Alkis y Temizel (2015) mantiene una línea distinta a los demás. Partiendo de los estudios de Cialdini y Kaptein, plantearon un experimento en el cual, tras aplicar el Big Five a los sujetos, les administraron una segunda batería de ítems: STPS (Susceptibility To Persuasive Strategies scale, o escala de susceptibilidad a las estrategias persuasivas) (Kaptein, 2012). Con esta escala, se puso a prueba la efectividad de cada uno de los principios de persuasión de Cialdini (1987) a cada sujeto, encontrando diferentes correlaciones significativas entre estos y los rasgos de personalidad del Big Five (ver la tabla 3).

Tabla 3. Correlación entre las variables del Big Five y la STPS. Adaptada de Alkis y Temizel (2015)

\begin{tabular}{ccccccc}
\hline \hline & $\mathrm{R}$ & $\mathrm{E}$ & $\mathrm{A}$ & $\mathrm{SS}$ & $\mathrm{S}$ & $\mathrm{C}$ \\
\hline \hline Extraversión & 0.14 & 0.25 & & & 0.12 & \\
\hline Cordialidad & 0.2 & & 0.25 & 0.10 & 0.29 & 0.15 \\
\hline Responsabilidad & 0.14 & & 0.23 & & -0.12 & 0.31 \\
\hline Neuroticismo & 0.12 & 0.17 & & & & \\
\hline $\begin{array}{c}\text { Apertura a la } \\
\text { experiencia }\end{array}$ & & & -0.2 & -0.22 & -0.12 & 0.12 \\
\hline \hline
\end{tabular}

De sus datos se concluye que los extrovertidos (extroversión y apertura) se ven más influidos por los principios de reciprocidad ( $R$ en la tabla), escasez (E), simpatía (S) y compromiso (C), mientras que los introvertidos son más vulnerables a la autoridad (A) y la sanción social (SS). Por otra parte, parece que los sujetos con alto neuroticismo se muestran más susceptibles a la escasez y reciprocidad. Los sujetos cordiales y responsables son más persuadidos por los principios de reciprocidad, autoridad, y compromiso, dándose más efectividad de la simpatía en los sujetos cordiales, al contrario que en los altos en responsabilidad (Alkis y Temizel, 2015).
Posteriormente, Oyibo, Orji y Vassileva (2017) replicaron este estudio, obteniendo resultados distintos (ver tabla 4), al encontrarse una mayor influencia de la autoridad, sanción social y simpatía en los sujetos introvertidos (baja apertura), una vulnerabilidad a la sanción social por parte de los sujetos neuróticos, y una mayor efectividad de la reciprocidad, y compromiso en sujetos responsables, y de autoridad y simpatía en sujetos cordiales (Oyibo et al., 2017). Las diferencias en los resultados se pueden deber a la homogeneidad en la muestra empleada en el estudio de Alkis y Temizel (2015).

Tabla 4. Correlación entre las variables del Big Five y la STPS. Adaptada de Oyibo et al. (2017) (Traducido)

\begin{tabular}{lcccccc}
\hline \hline & $\mathrm{R}$ & $\mathrm{E}$ & $\mathrm{A}$ & $\mathrm{SS}$ & $\mathrm{S}$ & $\mathrm{C}$ \\
\hline \hline Extraversión & & & & & & \\
\hline Cordialidad & & 0,25 & & 0,19 & 0,18 \\
\hline Responsabilidad & 0,25 & & & & $-0,36$ & 0,17 \\
\hline Neuroticismo & & & 0,27 & & \\
\hline $\begin{array}{c}\text { Apertura a la } \\
\text { experiencia }\end{array}$ & & $-0,14$ & $-0,18$ & $-0,17$ & \\
\hline \hline
\end{tabular}

Sofia, Marianna, George y Panos (2016) replicaron el experimento de Kaptein (2012) en el cual se les presentaba una serie de portadas de películas acompañadas de información que hacía referencia a los distintos principios de persuasión. Al comparar los resultados de este experimento con las puntuaciones de los sujetos en el Big Five, encontraron que los sujetos extrovertidos parecían ser más influenciable a nivel general debido a su tendencia a ser más sociables y buscar más estimulación, siendo especialmente vulnerables al principio de simpatía. Por otra parte, observaron que los sujetos con alta cordialidad y responsabilidad eran más influidos por la reciprocidad, siendo los sujetos menos responsables más vulnerables al compromiso. Por último, destacaron la mayor influencia de los principios de sanción social y compromiso en los sujetos más neuróticos, mientras que la simpatía parecía ser más efectiva en sujetos estables.

En paralelo, Smith, Denis y Masthoff (2016) realizan un estudio similar. Si bien estos no emplearon la STPS, utilizaron mensajes que se ajustaban a cada una de las estrategias de persuasión, encontrando que los bajos en neuroticismo, y los altos en cordialidad, valoraban mejor en general todas las estrategias. Igualmente, encontraron una preferencia hacia la autoridad por parte de los altos en responsabilidad, mientras que los bajos en este rasgo preferían la alusión a la escasez.

Thomas, Masthoff y Oren (2017) emplearon también mensajes ajustados a estas estrategias, pero sin emplear las 
de escasez ni reciprocidad. Además, emplearon mensajes en sentido positivo y negativo. Estos encontraron que los altos en extroversión y responsabilidad, y bajos en apertura a la experiencia respondían mejor a todas las estrategias.

\section{CONCLUSIONES}

Se pueden observar ciertos perfiles tendentes a una mayor vulnerabilidad al cambio de actitudes. Si bien las teorías pertenecientes a la psicología social permiten elaborar una gran cantidad de técnicas eficaces en el cambio de actitudes, adecuar su elección y uso al receptor favorecerá el aumento de la ratio de éxito (Kaptein, 2015).

Teniendo como base el ELM, la ruta por la que se procese la información dependerá de la capacidad del sujeto, su inteligencia, su implicación en el tema y su motivación. Sin embargo, estas variables pueden verse determinadas, en parte, por factores diferenciales del individuo. En particular, por su personalidad.

Su motivación y predisposición, así como capacidad de elaboración de la información en dadas situaciones, estará determinada por la interacción entre las características del sujeto y la temática del mensaje, así como su modalidad, método de transmisión de información, o características de la fuente.

Los sujetos introvertidos parecen más resistentes al cambio debido a su falta de impulsividad. Estos meditan más, procesando y analizando más la situación, lo cual les permite generar actitudes más resistentes al cambio, siendo mucho más efectivo el empleo de la vía central para el éxito en la persuasión (Chen y Lee, 2008). El extrovertido resulta mucho más activo, impulsivo, y con una tendencia algo menor al procesamiento de la información, siendo más susceptible a la vía periférica. Por otra parte, los mensajes que sugieran o proporcionen estimulación serán más atractivos para éstos, del mismo modo que tenderán a aceptar los mensajes que impliquen un componente social (de Vries et al., 2017). Pero no solo se trata del mensaje, sino que un emisor que se muestre más activo, sociable y estimulante (extrovertido), resultará más atractivo para este tipo de sujetos.

Los sujetos más neuróticos parecen tener ciertas vulnerabilidades, siendo necesario tener en cuenta su estado de ánimo (Cai et al., 2014). Al tener una autoestima más baja, son más susceptibles al cambio por una tendencia a valorar sus propias actitudes como menos válidas que las de los demás (Oreg y Sverdlik, 2014). Esto les convierte en blancos más fáciles para mensajes que apelen a la culpabilidad, o para indicadores periféricos que reflejen cierta superioridad del emisor con respecto a ellos (DeBono y McDermott, 1994; Zellner, 1970). Sin embargo, la ansiedad supone un componente desestabilizador para ellos, siendo más eficiente recurrir a la vía periférica (Briñol y Petty, 2005). Además, teniendo en cuenta las necesidades y preocupaciones del sujeto neurótico, los argumentos dirigidos a un aumento de la seguridad y el control podrían tener gran peso en la aceptación del mensaje, pues estos se preocupan de más por las consecuencias futuras (Shakarchi y Haugtvedt, 2004).

Por su parte, los sujetos más empáticos, con gran capacidad de ponerse en el lugar del otro, pueden ser más fáciles de persuadir (Salceanu, 2014). Su facilidad para hallar una similaridad con el receptor podría hacerles más vulnerables de manera general.

La necesidad de cognición puede suponer un obstáculo para la persuasión. Los sujetos con alta tendencia a este rasgo parecen resistentes al cambio actitudinal, elaborando en gran medida la información, y generando actitudes de gran fuerza que requieren argumentos igualmente fuertes para cambiarlos (Petty y Morris,1983). Por otra parte, esto les hace resistentes a indicadores periféricos, lo que implica mayor probabilidad de cambio a través de los argumentos de mayor complejidad y peso.

Se destacan los hallazgos de Alkis y Temizel (2015), Sofia et al. (2016), Smith et al. (2016), Thomas et al. (2017) y Oyibo et al. (2017). Estudiando las estrategias de persuasión más extendidas en la actualidad (Cialdini, 1987), estos investigadores logran extraer las diferencias de vulnerabilidad a cada una en función de la personalidad. Sin embargo, resalta la discordancia de los resultados de estos artículos. A priori, esta incongruencia se atribuye a las diferencias culturales entre las muestras, el reducido tamaño muestral en algunos de estos y a la diferencia en los paradigmas experiementales. Asimismo, el estudio psicométrico (Alkis y Temizel, 2015; Kaptein, 2012; Oyibo et al., 2017) puede estar simplificando principios que se caracterizan por una gran complejidad, no siendo capaz de medirlos adecuadamente. El empleo de un paradigma experimental de carácter conductual podría facilitar el aislamiento de las variables extrañas, explicando mejor la relación entre los rasgos y las vulnerabilidades a persuasión.

Así, partiendo de los resultados observados a lo largo 
de la revisión, del extendido uso de las estrategias de persuasión de Cialdini (1987), y de los estudios de personalidad en relación a los mismos, cabe terminar este artículo formulando las siguientes propuestas, en las que seguir profundizando.

Reciprocidad. Los sujetos con un mayor nivel de empatía, sintiéndose a su vez más responsables, tenderán a devolver el favor. Además, los sujetos con altos niveles de extroversión, viéndose atraídos por mensajes que conlleven un componente social (de Vries et al., 2017), tenderán a responder a la ley de reciprocidad, ganando simpatía la fuente de persuasión.

Escasez: Por un lado, los sujetos con un mayor nivel de extroversión, buscadores de sensaciones, al ver en el objeto escaso un estímulo intenso, se sentirían más atraídos por él que los sujetos introvertidos. Por su parte, los sujetos con alto neuroticismo se ven especialmente afectados por la posibilidad de perder la oportunidad, siendo más vulnerables.

Sanción social. Un componente clave del neuroticismo es la inseguridad, especialmente cuando va acompañado del rasgo introversión, generando sujetos que tienden a "dejarse llevar" (de Juan y García, 2004). De este modo, será este tipo de personalidad la más vulnerable a la sanción social.

Autoridad. Teniendo en cuenta el modelo de Eysenck (1990), los sujetos con la empatía alta, o de psicoticismo bajo, serían más responsables, y por tanto, más susceptibles al poder de la autoridad. Además, los sujetos más neuróticos, al ser más inseguros, tenderán a fiarse más de una autoridad que de su propio juicio (Oreg y Sverdlik, 2014).

Coherencia o compromiso. Se plantea la especial vulnerabilidad de los sujetos con baja empatía, aquellos con un carácter más egocéntrico, con mayor autoestima (Eysenck y Bordas, 1970). Estos tenderán a anclarse más en sus propias palabras, comprometiéndose con ellas ("cuando digo algo, lo cumplo").

Simpatía. Los sujetos se sentirán más atraídos por un emisor con una personalidad similar a la suya (Igartua, 2010; Komeda et al., 2013). Los extrovertidos, ante una búsqueda de estimulación, encontrarán más atrayente a un comunicador más activo, del mismo modo que los sujetos más neuróticos se sentirán más atraídos por aquellos interlocutores que muestren un mensaje más emocional. Por otra parte, se espera que los sujetos más empáticos sean más vulnerables a la simpatía inducida o artificial, siendo estos más afables (Eysenck y Bordas, 1970). Por último, destacar que aquellos sujetos con una empatía más baja, y más egocéntricos (Eysenck y Bordas, 1970) serán más susceptibles a los elogios.

\section{REFERENCIAS}

Albarracín, D., Johnson, B. T., \& Zanna, M. P. (2014). The handbook of attitudes. Londres: Psychology Press.

Alkış, N., \& Temizel, T. T. (2015). The impact of individual differences on influence strategies. Personality and Individual Differences, 87, 147152. doi: $10.1016 /$ j.paid.2015.07.037

Aluja, A., García, O., \& García, L. F. (2002). A comparative study of Zuckerman's three structural models for personality through the NEO-PI-R, ZKPQ-III-R, EPQ-RS and Goldberg's 50-bipolar adjectives. Personality and Individual Differences, 33(5), 713-725. doi: 10.1016/S0191-8869(01)00186-6

Berzonsky, M. D. (1989). Identity style: Conceptualization and measurement. Journal of adolescent research, 4(3), 268-282. doi: 10.1177/074355488943002

Berzonsky, M. D., \& Sullivan, C. (1992). Social-cognitive aspects of identity style: Need for cognition, experiential openness, and introspection. Journal of Adolescent Research,7(2), 140-155. doi: $10.1177 / 074355489272002$

Briñol, P., Becerra, A., Díaz, D., Valle, C., Horcajo, J., \& Gallardo, I. (2005). El efecto de la necesidad de cognición sobre la influencia interpersonal. Psicothema, 17(4).

Briñol, P., De la Corte, L., \& Becerra, A. (2001). Qué es persuasión. Madrid: Biblioteca Nueva.

Briñol, P., \& Petty, R. E. (2005). Individual Differences in Attitude Change. En D. Albarracín, B. T. Johnson, M. P. Zanna. The bandbook of attitudes (pp. 575-615). Mahwah, NJ, US: Lawrence Erlbaum Associates Publishers.

Cacioppo, J. T., \& Petty, R. E. (1982). The need for cognition. Journal of Personality and Social Psychology, 42(1), 116-131. doi: 10.1037/0022-3514.42.1.116

Cai, Y., Pan, L., \& He, J. (2014). Self or other: Compatibility between emotion and message referent. Social Behavior and Personality: an international journal, 42(9), 1575-1584. doi: 10.2224/sbp.2014.42.9.1575

Carment, D. W., Miles, C. G., \& Cervin, V. B. (1965). Persuasiveness and persuasibility as related to intelligence and extraversion. British Journal of Clinical Psychology, 4(1), 1-7. doi: 10.1111/j.20448260.1965.tb00433.x

Cattell, R. B., \& P. Cattell, H. E. (1995). Personality structure and the new fifth edition of the 16PF. Educational and Psychological Measurement, 55(6), 926-937. doi: 10.1177/0013164495055006002

Chen, S. H., \& Lee, K. P. (2008). The role of personality traits and perceived values in persuasion: An elaboration likelihood model perspective on online shopping. Social Behavior and Personality: an international journal, 36(10), 1379-1399. doi: 10.2224/sbp.2008.36.10.1379

Cialdini, R. B. (1987). Influence. The psychology of persuasión. Nueva York: HarperCollins Publishers Inc.

Cloninger, S. (2003). Teorias de la personalidad. México: Prentice Hall México.

de Vries, R. A., Truong, K. P., Zaga, C., Li, J., \& Evers, V. (2017). A Fundación Universitaria Behavior \& Law $\mid 17$ 
Sánchez-Muñoz, I., Calcerrada, M. L., González, J.L. \& de Juan, M. (2018). Persuasión y personalidad. El receptor en la comunicación persuasiva. Behavior er Law Journal, 4(1), 9-20.

word of advice: how to tailor motivational text messages based on behavior change theory to personality and gender. Personal and Ubiquitous Computing, 1-13. doi: 10.1007/s00779-017-1025-1

DeBono, K. G., \& McDermott, J. B. (1994). Trait anxiety and persuasion: Individual differences in information processing strategies. Journal of Research in Personality, 28(3), 395-407. doi: 10.1006/jrpe.1994.1028

Eaves, L., \& Eysenck, H. (1975). The nature of extraversion: A genetical analysis. Journal of personality and social psychology, 32(1), 102. doi: $10.1037 / \mathrm{h} 0076862$

De Juan, M., \& García, L. F. (2004). Nuestra personalidad. En qué y por qué somos diferentes. Madrid: Biblioteca Nueva.

Eysenck, H. J. (1990). Genetic and environmental contributions to individual differences: The three major dimensions of personality. Journal of personality, 58(1), 245-261. doi: 10.1111/j.1467-6494.1990.tb00915.x

Eysenck, H. J., \& Bordas, M. D. (1970). Fundamentos biológicos de la personalidad. Barcelona: Fontanella.

Eysenck, H. J., \& Eysenck, S. B. (1967). On the unitary nature of extraversion. Acta Psychologica, 26, 383-390. doi: 10.1016/00016918(67)90034-0

Eysenck, S. B., \& Eysenck, H. J. (1970). Crime and personality an empirical study of the three-factor theory. The British Journal of Criminology, 10(3), 225-239.

Falces, C., Briñol, P., Sierra, B., Becerra, A., \& Alier, E. (2001). Validación de la escala de necesidad de cognición y su aplicación al estudio del cambio de actitudes. Psicothema, 13(4).

Germeijs, V., \& Verschueren, K. (2011). Indecisiveness and Big Five personality factors: Relationship and specificity. Personality And Individual Differences, 50(7), 1023-1028. doi: 10.1016/j.paid.2011.01.017

Glenn, A. L., \& Raine, A. (2014). Psychopathy: An introduction to biological findings and their implications. Nueva York: NYU Press.

Greenwald, A. G. (1968). Cognitive learning, cognitive response to persuasion, and attitude change. Psychological foundations of attitudes, $147-170$.

Gutierrez, J., Bajen, M. J., Sintas, F., \& Amat, M. (1993). Evaluación de la tendencia al esfuerzo cognitivo. Anuario de psicologia/The UB Journal of psychology, (58), 53-68.

Hagemann, D., Hewig, J., Walter, C., Schankin, A., Danner, D., \& Naumann, E. (2009). Positive evidence for Eysenck's arousal hypothesis: A combined EEG and MRI study with multiple measurement occasions. Personality and Individual Differences, 47(7), 717-721. doi: 10.1016/j.paid.2009.06.009

Halko, S., \& Kientz, J. A. (2010, June). Personality and persuasive technology: an exploratory study on health-promoting mobile applications. In International conference on persuasive technology (pp. 150-161). Springer, Berlin, Heidelberg.

Haugtvedt, C. P., \& Petty, R. E. (1992). Personality and persuasion: Need for cognition moderates the persistence and resistance of attitude changes. Journal Of Personality And Social Psychology, 63(2), 308-319. doi: 10.1037/0022-3514.63.2.308

Hepler, J., \& Albarracin, D. (2013). Attitudes without objects: Evidence for a dispositional attitude, its measurement, and its consequences. Journal of Personality and Social Psychology, 104(6), 1060. doi: $10.1037 / \mathrm{a} 0032282$

Higbee, K. L. (1969). Fifteen years of fear arousal: research on threat appeals: 1953-1968. Psychological Bulletin, 72(6), 426-444. doi: $10.1037 / \mathrm{h} 0028430$

Hirsh, J. B., Kang, S. K., \& Bodenhausen, G. V. (2012). Personalized persuasion: tailoring persuasive appeals to recipients' personality traits. Psychological Science, 23(6), 578-581. doi: 10.1177/0956797611436349

Hodson, G., \& Sorrentino, R. M. (1999). Uncertainty orientation and the Big Five personality structure. Journal of Research in Personality, 33(2), 253-261. doi: 10.1006/jrpe.1999.2244

Hovland, C. I., Janis, I. L., \& Kelley, H. H. (1953). Communication and persuasion; psychological studies of opinion change. Yale University Press.

Hovland, C. I., Lumsdaine, A. A., \& Sheffield, F. D. (1949). Experiments on mass communication. (Studies in social psychology in World War II). Princeton University Press.

Igartua, J. J. (1998). La técnica del listado de pensamientos como método de investigación en comunicación publicitaria The thought-listing technique as a research method in advertising. Comunicación y Cultura, 2(1), 43-62. doi: $10.1174 / 113839598322011860$

Igartua, J. J. (2010). Identification with characters and narrative persuasion through fictional feature films. The European Journal of Communication Research. doi: 10.1515/comm.2010.019

Janis, I. L. (1954). Personality correlates of susceptibility to persuasion. Journal of Personality, 22(4), 504-518. doi: 10.1111/j.1467-6494.1954.tb01870.x

Kaptein, M. (2012). Personalized persuasion in ambient intelligence. Journal of Ambient Intelligence and Smart Environments, 4(3), 279-280.

Kaptein, M. (2015). Persuasion profiling: how the internet knows what makes you tick. Amsterdam: Business Contact.

Kaptein, M., \& Eckles, D. (2012). Heterogeneity in the effects of online persuasion. Journal of Interactive Marketing, 26(3), 176-188.

Kaptein, M., Markopoulos, P., de Ruyter, B., \& Aarts, E. (2009). Can you be persuaded? individual differences in susceptibility to persuasion. Human-computer interaction-INTERACT, 115-118.

Komeda, H., Tsunemi, K., Inohara, K., Kusumi, T., \& Rapp, D. N. (2013). Beyond disposition: the processing consequences of explicit and implicit invocations of empathy. Acta Psychologica, 142(3), 349-355. doi: 10.1016/j.actpsy.2013.01.002

Leventhal, H., \& Trembly, G. (1968). Negative emotions and persuasion. Journal of Personality, 36(1), 154-168. doi: 10.1111/j.1467-6494.1968.tb01466.x

McCrae, R. R., Costa, P. T., \& Piedmont, R. L. (1993). Folk Concepts, Natural Language, and Psychological Constructs: The California Psychological Inventory and the Five-Factor Model. Journal of Personality, 61(1), 1-26. doi: 10.1111/j.1467-6494.1993.tb00276.x

McGuire, W. J. (1985). Attitudes and attitude change. Handbook of social psychology, 2.

Millman, S. (1968). Anxiety, comprehension, and susceptibility to social influence. Journal of Personality and Social Psychology, 9(3), 251. doi: $10.1037 / \mathrm{h} 0021252$

Moreno, B. (2007). Psicología de la personalidad: Procesos. Madrid: Ediciones Paraninfo.

Moya-Albiol, L., Herrero, N., \& Bernal, M. C. (2010). Bases neuronales de la empatía. Rev Neurol, 50(2), 89-100.

Oreg, S., \& Sverdlik, N. (2014). Source personality and persuasiveness: 
Big Five predispositions to being persuasive and the role of message involvement. Journal Of Personality, 82(3), 250-264. doi: 10.1111/jopy.12049

Oyibo, K., Orji, R., \& Vassileva, J. (2017). Investigation of the Influence of Personality Traits on Cialdini's Persuasive Strategies. In International Workshop on Personalizing in Persuasive Technologies.

Páez, D., Fernández, I., Ubillos, S., \& Zubieta, E. (2004). Psicología social, cultura y educación. Nueva Jersey: Pearson Prentice Hall.

Petty, R. E., \& Cacioppo, J. T. (1986). The elaboration likelihood model of persuasion. Advances in experimental social psychology, 19, 123-205. doi: 10.1016/S0065-2601(08)60214-2

Petty, R. E., \& Morris, K. J. (1983). Effects of need for cognition on message evaluation, recall, and persuasion. Journal of Personality and Social Psychology, 45(4), 805-818. doi: 10.1037/0022-3514.45.4.805

Petty, R. E., \& Wegener, D. T. (1998). Attitude change: Multiple roles for persuasion variables. En D. Gilbert, S. Fiske, \& G. Lindzey. The handbook of social psychology (pp. 323-390).

Petty, R. E., \& Wegener, D. T. (1999). The elaboration likelihood model: Current status and controversies. En S. Chaiken \& Trope. Dual-process theories in social psychology (pp. 37-72). New York: Guilford Press

Petty, R. E., Cacioppo, J. T., \& Goldman, R. (1981). Personal involvement as a determinant of argument-based persuasion. Journal of personality and social psychology, 41(5), 847. doi: 10.1037/0022-3514.41.5.847

Robinson, K. F. (1941). An experimental study of the effects of group discussion upon the social attitudes of college students. Communications Monographs, 8(1), 34-57.

Sălceanu, C. (2014). Personality factors and resistance to the manipulation of advertising. Procedia-Social and Behavioral Sciences, 127, 5-9. doi: 10.1016/j.sbspro.2014.03.202

Shakarchi, R. J., \& Haugtvedt, C. P. (2004). Differentiating Individual Differences in Resistance to Persuasion. En E. S. Knowles, J. A. Linn, E. S. Knowles, J. A. Linn. Resistance and persuasion (pp. 105113). Mahwah, NJ, US: Lawrence Erlbaum Associates Publishers.

Smith, K. A., Dennis, M. y Masthoff, J. (2016). Personalizing reminders to personality for melanoma self-checking. En Proceedings of the 2016 Conference on User Modeling Adaptation and Personalization (pp. 85-93). ACM.

Sofia, G., Marianna, S., George, L., \& Panos, K. (2016, August). Investigating the role of personality traits and influence strategies on the persuasive effect of personalized recommendations. In 4th Workshop on Emotions and Personality in Personalized Systems (EMPIRE) (p. 9).

Shen, L. (2011). The effectiveness of empathy-versus fear-arousing antismoking PSAs. Health communication, 26(5), 404-415. doi: 10.1080/10410236.2011.552480

Sorrentino, R. M., Bobocel, D. R., Gitta, M. Z., Olson, J. M., \& Hewitt, E. C. (1988). Uncertainty orientation and persuasion: Individual differences in the effects of personal relevance on social judgments. Journal of Personality and social Psychology, 55(3), 357. doi: 10.1037/0022-3514.55.3.357

Thomas, R. J., Masthoff, J. y Oren, N. (2017). Adapting healthy eating messages to personality. En International Conference on Persuasive Technology (pp. 119-132). Springer, Cham.

Vázquez, A. y Gómez, A. (2018). Psicología Social. Madrid: Sanz y Torres.

Zellner, M. (1970). Self-esteem, reception, and influenceability. Journal Of Personality And Social Psychology, 15(1), 87-93. doi: $10.1037 /$ h0029201 
Sánchez-Muñoz, I., Calcerrada, M. L., González, J.L. \& de Juan, M. (2018). Persuasión y personalidad. El receptor en la comunicación persuasiva. Behavior \& Law Journal, 4(1), 9-20.

\section{ANEXO 1}

Tabla 1. Tabla del número de artículos encontrados en cada búsqueda

\begin{tabular}{|c|c|c|c|c|c|}
\hline Busqueda & Filtro & EBSCO & SD & WoS & Total \\
\hline \multirow[t]{3}{*}{ B1 } & Personality (ABSTRACT) AND Persuasion (ABSTRACT) & 284 & 30 & 341 & \\
\hline & Refinado: AN Personality (SU DESCRIPTORES) & 136 & & & \\
\hline & Selección & 17 & 4 & 0 & 21 \\
\hline \multirow[t]{2}{*}{ B2 } & Personality (T TITLE) AND Persuasion (T TITLE) & 15 & 3 & 14 & \\
\hline & Selección & 5 & 0 & 1 & 6 \\
\hline \multirow[t]{2}{*}{ B3 } & Personality (SU DESCRIPTORES) AND Cialdini (AU AUTORES) & 8 & 0 & 2 & \\
\hline & Selección & 2 & 0 & 0 & 2 \\
\hline \multirow[t]{3}{*}{ B4 } & Personality (SU DESCRIPTORES) AND Petty (AU AUTORES) & 118 & 2 & 36 & \\
\hline & Refinado: AND Persuasion (SU DESCRIPTORES) & 2 & & & \\
\hline & Selección & 1 & 0 & 1 & 2 \\
\hline \multirow[t]{3}{*}{ B5 } & Individual Differences (ABSTRACT) AND Persuasion (ABSTRACT) & 143 & 21 & 417 & \\
\hline & & & & 61 & \\
\hline & Selección & 9 & 1 & 3 & 13 \\
\hline \multirow[t]{3}{*}{ B6 } & Individual Differences (SU DESCRIPTORES) AND Persuasion (SU DESCRIPTORES) & 42 & 2 & 417 & \\
\hline & & & & 69 & \\
\hline & Selección & 6 & 0 & 0 & 6 \\
\hline \multirow[t]{2}{*}{ B7 } & Individual Differences (SU DESCRIPTORES) AND Petty (AU AUTORES) & 16 & 0 & 46 & \\
\hline & Selección & 2 & 0 & 0 & 2 \\
\hline \multirow[t]{3}{*}{ B8 } & Attitude Change (SU DESCRIPTORES) AND Personality (SU DESCRIPTORES) & 592 & 2 & 1128 & \\
\hline & Refinado: Persuasion (TXT TEXTO COMPLETO) & 44 & & 30 & \\
\hline & & 2 & 0 & 0 & 2 \\
\hline \multirow[t]{2}{*}{ B9 } & Extraversion (ABSTRACT) AND Persuasion (ABSTRACT) & 11 & 3 & 19 & \\
\hline & & 1 & 0 & 3 & 4 \\
\hline \multirow[t]{2}{*}{ B10 } & Empathy (ABSTRACT) AND Persuasion (SU DESCRIPTORES) & 22 & 2 & 86 & \\
\hline & & 1 & 0 & 4 & 5 \\
\hline \multirow[t]{2}{*}{ B11 } & Personality (SU DESCRIPTORES) AND Cacioppo (AU AUTORES) & 37 & 3 & 10 & \\
\hline & Selección & 1 & 0 & 0 & 1 \\
\hline \multirow[t]{2}{*}{ B12 } & Personality (SU DESCRIPTORES) AND Albarracin (AU AUTORES) & 8 & 0 & 6 & \\
\hline & Selección & 1 & 0 & 0 & 1 \\
\hline \multirow[t]{2}{*}{ B13 } & Personality (SU DESCRIPTORES) AND Igartua (AU AUTORES) & 3 & 0 & 1 & \\
\hline & Selección & 1 & 0 & 0 & 1 \\
\hline Total & & & & & 66 \\
\hline
\end{tabular}

